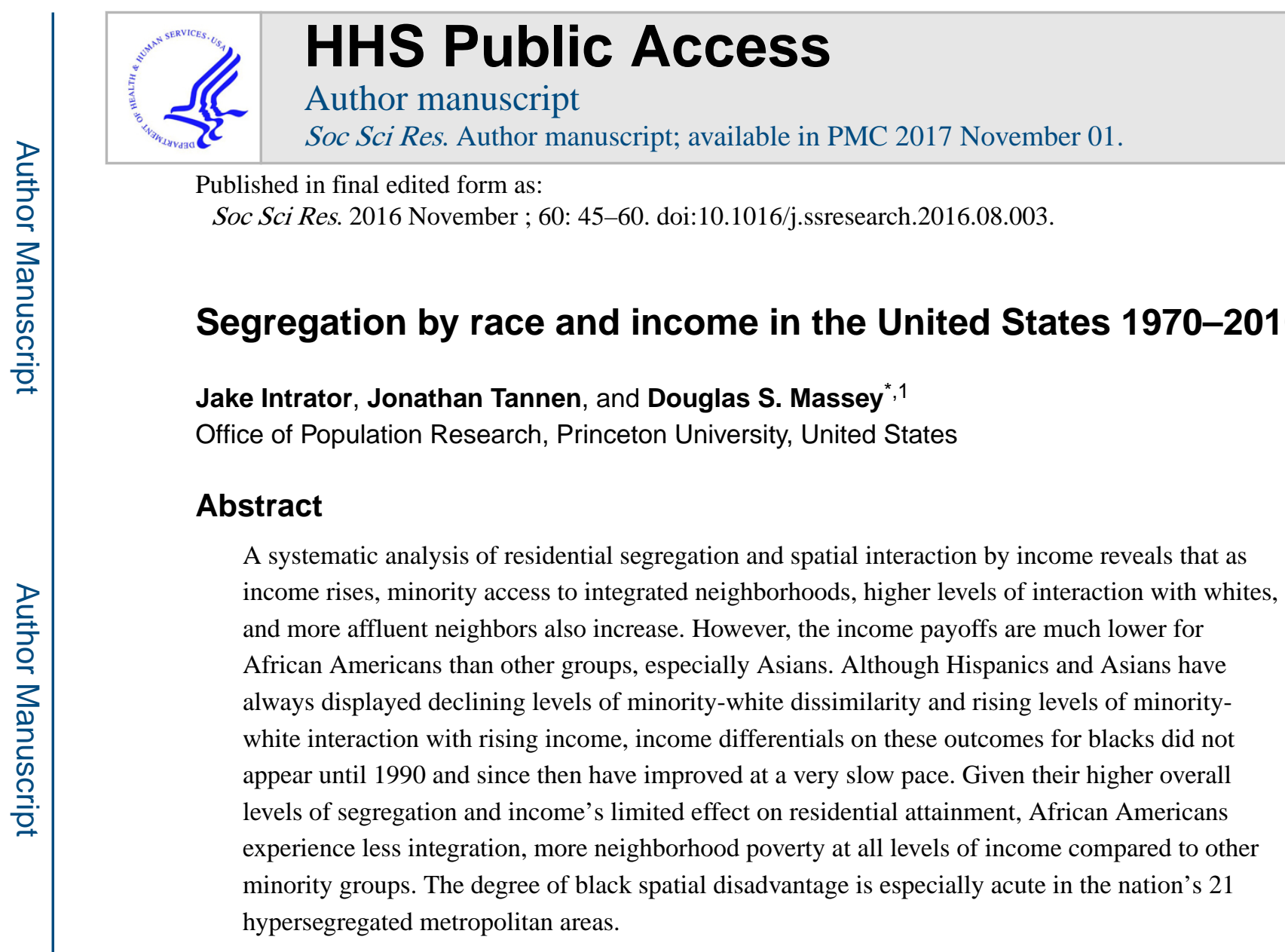

In any society opportunities and resources are unevenly distributed in space, requiring geographic mobility for people to access them fully. In metropolitan America this mobility is expressed as movement within and between neighborhoods. In capitalist societies, spatially dispersed resources are accessed primarily through housing markets, which not only allocate households to dwellings through the mechanism of market pricing but also allot people to neighborhoods and the socioeconomic environments they foster. As a result, housing markets not only distribute access to homes, but also access to education, safety, security, wealth, health, peer groups, social networks, and prestige (see Massey and Denton, 1993; Sampson, 2012). Given the legacy of racial segregation in the United States and the recent increase in class segregation Reardon and Bischoff 2011a), American housing markets are now characterized by a high degree of segmentation on the basis of race and class, thus stratifying access to societal resources by socioeconomic status and skin color (Sharkey, 2013; Massey and Brodmann, 2014).

Two principal conceptual frameworks have been employed by sociologists to analyze segregation and residential mobility in urban America: the spatial assimilation model and the place stratification perspective. The former argues that as individuals and households in different racial and ethnic groups accumulate financial, social, and cultural capital they draw upon these resources to gain access to more advantaged residential areas characterized by better schools, safer streets, lower insurance rates, healthier surroundings, and more

\footnotetext{
"Corresponding author. Office of Population Research, Wallace Hall, Princeton University, Princeton, NJ 08544, United States. dmassey@princeton.edu (D.S. Massey).

${ }^{1}$ The authors would like to thank the National Institute of Child Health and Human.
} 
salubrious peer groups, thereby bringing about their progressive integration into society (Massey and Mullan, 1984; Massey and Denton, 1985). The spatial assimilation model parallels the neoclassical model in economics, which argues that in competitive market societies people rationally act to translate resources into improved residential circumstances, subject to the constraints of taste and budget (McDonald and McMillen, 2010). Other things equal, then, we expect to observe a positive relationship between household income and neighborhood quality.

Of course, other things are not equal and, as already noted, U.S. housing markets are segmented by race and class, a fact taken into account by the place stratification model, which argues that neighborhoods not only differ with respect to opportunities and resources, but that access to places of advantage and disadvantage is itself structured by race and class (Logan and Molotch, 1987; Alba and Logan, 1992). Unequal access to neighborhood opportunities and resources is brought about through processes of individual and institutional discrimination stemming from class bias and racial prejudice among people and institutions (Massey and Denton, 1993; Charles, 2003). Historically, the most privileged ecological spaces in urban America have been those in which white households predominate. Thus we expect to observe differences in access to predominately white neighborhoods by race, holding income constant. Neighborhood privilege is also reflected in class composition, and we also expect to observe racial differences in exposure to socioeconomic advantage and disadvantage, irrespective of income.

In this analysis, we examine trends in racial segregation by income in the United States from 1970 through 2010 . We begin by reviewing recent research on racial segregation by socioeconomic status and after describing our data and methods we move on to report the degree to which African Americans, Hispanics, and Asians in different income classes are segregated from whites and others of the same income regardless of race. We then measure the degree to which different race-class groups are exposed to spatially concentrated poverty and affluence. We complete our analysis by estimating multivariate models to determine how structural features of the metropolitan environment affect the ability to assimilate spatially as income rises and conclude with a summary of findings and a discussion of their implications.

\section{Segregation and socioeconomic status}

The study of socioeconomic status, race, and residential location has a long history in sociology, going back to the early work of researchers at the University of Chicago (Park and Burgess, 1921; Park et al., 1925). Research has generally found that European immigrants and their descendants conformed closely to the classic model of spatial assimilation, progressively integrating within mainstream society as incomes roses and generations passed. Although in the early 20th century Southern and Eastern European groups (e.g. Italians, Poles, and Russian Jews) were more segregated than Northern and Western European groups (Irish, Germans, and Scandinavians), over time all European ethnic groups experienced progress toward residential integration, though admittedly at different rates. Nonetheless, as generations in the United States increased and 
socioeconomic status rose, levels of European ethnic segregation steadily fell over time (Lieberson, 1963, 1980; Massey, 1985; Alba and Nee, 2003).

The degree of European assimilation, spatial and otherwise, was such that by the 1980s Italian Americans were said to be moving into "the twilight of ethnicity" (Alba, 1985) and people of European origin experienced ethnicity as an "option" rather than an ascription (Waters, 1990). In contrast, levels of residential segregation for African Americans reached heights in the early 20th century that were never experienced by European groups and these high levels persisted for decades, remaining impervious to the effects of socioeconomic status or the number of generations of urban residence (Duncan and Duncan, 1957; Taeuber and Taeuber, 1965; Lieberson, 1981; Massey and Denton, 1993).

With the revival of immigration after 1965, research increasingly focused on the residential segregation of Hispanics and Asians as well as African Americans. Although levels of black residential segregation moved slowly downward during the 1970s and 1980s, they nonetheless remained quite high and continued to be unaffected by socioeconomic status. In contrast, segregation levels for Hispanics and Asians generally ranged from low to moderate and displayed clear declines across generations and with rising socioeconomic status (Massey, 1979a, 1979b, 1981; Massey and Denton, 1987, 1988a). The distinctive nature of black segregation was underscored by the fact that black and mixed race Hispanics from the Caribbean were far more segregated than their white counterparts (Massey and Bitterman, 1985; Denton and Massey, 1989) and that African Americans, alone among racial-ethnic groups, evinced a distinctive pattern of intense of isolation across multiple geographic dimensions that Massey and Denton (1989) termed "hypersegregation."

During the 1990s, however, patterns of black segregation began to shift. Although hypersegregation persisted in many metropolitan areas (Wilkes and Iceland, 2004), on average black segregation continued to decline (Iceland et al., 2002; Rugh and Massey, 2014) and hypersegregation became less common over time (Massey and Tannen, 2015). Moreover, in 1990 African Americans began to display a pattern of declining segregation with rising socioeconomic status (Massey and Fischer, 1999), one that continued into the new century (Iceland 2005; Iceland and Wilkes, 2006). As racial segregation in U.S. metropolitan areas moderated, however, the degree of segregation on the basis of income increased to complicate the picture (Reardon and Bischoff, 2011a, 2011b; Reardon et al., 2015).

Other things equal, rising income segregation is expected to increase the degree of socioeconomic inequality across neighborhoods; but racial disparities in neighborhood inequality are more strongly influenced by racial residential segregation and racial differences in income. Firebaugh and Farrell (2016) have shown that moderating racial segregation and declining income differences between racial groups generally worked to reduce the overall level of metropolitan neighborhood inequality by race in recent decades, especially for blacks whose segregation levels fell most dramatically (see Timberlake, 2002; Timberlake and Iceland, 2007; Osypuk et al., 2009). Here we focus not on changing levels of neighborhood inequality per se, but on the degree to which members of different racial- 
ethnic groups are able to convert their achieved income gains into integration with whites and improved neighborhood circumstances within metropolitan America.

Historically, the translation of socioeconomic achievements into residential improvements has been the principal mechanism by which poor racial and ethnic groups have achieved spatial assimilation in the United States, and moved on to achieve broader social and economic integration within U.S. society. Minority group members moved not so much because they wanted to live near native white Americans descendant from earlier immigrant arrivals, but because they wanted to access the benefits and resources that were disproportionately concentrated in native white neighborhoods: better schools, safer streets, higher home values, better municipal services, lower insurance rates, more inspiring peer environments, etc. As racial-ethnic groups acquired more income and greater education over time and across generations, they moved to gain access resources that would further enhance their mobility prospects, leading in the aggregate to declining levels of segregation and less neighborhood inequality among groups.

During the 1970s and 1980s, this interlocking pathway of spatial and social mobility was followed by Hispanics and Asians, just as it had been followed by earlier generations of southern and eastern European immigrants; but this pathway to mobility was largely foreclosed to African Americans whose ability to translate socioeconomic gains into spatial advantage was severely constrained by racial prejudice and discrimination (Massey and Mullan, 1984; Massey and Denton, 1985). As already noted, it was only in 1990 that we began to observe declines in black-white segregation with rising black income. In this analysis we seek to determine whether this pattern of desegregation with rising black income has continued into the 21 st century and the extent to which the historical access of Hispanics and Asians to white neighborhoods has persisted, especially given their rapid growth through mass immigration.

\section{Data and methods}

To measure residential segregation we use census tracts as our unit of analysis, drawing on data for 1970 through 2010 from Brown University's Longitudinal Tract Data Base (http:// www.s4.brown.edu/us2010/Researcher/LTBDDload/DataList.aspx), which was assembled from Decennial Censuses of Housing and Population. Census tracts are established by the U.S. Census Bureau in collaboration with local authorities to reflect prevailing social and geographic circumstances. They vary in size between 1200 and 8000 persons and average around 4000. Census tract boundaries can shift between censuses and thus complicate longitudinal analysis. Researchers often choose to ignore these changes (see Iceland et al., 2002) but here we draw on "crosswalk" data available from Brown University's database to redistribute data from past census iterations into units that follow current definitions, thereby creating a constant census tract grid.

We chose to measure socioeconomic status using income, which along with wealth is the primary resource that people take into real estate markets to optimize housing quality and neighborhood advantage. Tract data on race by household income were downloaded from the Social Explorer website (www.socialexplorer.com), which like the Brown database 
derived its figures from Decennial Censuses of Housing and Population from 1970 through 2000. For the year 2010, however, data came from the 2008-2012 American Community Surveys, which were aggregated to produce estimates centered on 2010. Tract data for Hispanics as well as non-Hispanic whites and blacks were available for the entire period but not for Asians in 1970 owing to census limitations so we begin charting their trends in 1980. All household incomes are expressed constant 2010 dollars and divided them into five categories corresponding to quintiles in the national distribution of household income.

Using these data, we computed measures of segregation by quintile of household income separately for metropolitan statistical areas throughout the United States. MSAs are defined by having one or more central cities of at least 50,000 inhabitants and are composed of any county containing a central city plus adjacent counties displaying a high degree of social and economic integration with central cities, as indicated by commuting patterns. We included in our dataset all MSAs that were consistently defined from 1970 through 2010, yielding a final dataset of 282 metropolitan areas (out of 381 MSAs currently defined by the Census Bureau). Thus trends in segregation reflect real changes in the spatial distribution of households classified by income and race, and not artifacts of shifting tract or metropolitan boundaries.

Segregation was measured first using the index of dissimilarity (D), which gives the relative percentage of minority group members and whites who would have to exchange tracts to achieve an even residential distribution (one in which each tract reflects the minoritymajority composition of the MSA as a whole). The index is defined by the formula:

$$
\mathrm{D}=\left(\frac{1}{2} \sum_{\mathrm{i}=1}^{\mathrm{n}}\left|\mathrm{x}_{\mathrm{i}} / \mathrm{X}-\mathrm{y}_{\mathrm{i}} / \mathrm{Y}\right|\right) \times 100
$$

where $x_{i}$ is the number of minority members in tract $i$ and $y_{i}$ is the number of whites in the same tract, $\mathrm{n}$ equals the total number of tracts, and $\mathrm{X}$ and Yare the total population of each group in the metropolitan area (Massey and Denton,1988b). The index varies from 0 to 100 and represents the percentage of minority and majority group members who would have to exchange tracts to achieve an even residential distribution.

In addition to dissimilarities, we also assess segregation by measuring the potential for intergroup interaction using the within-tract interaction index $\left({ }_{x} \mathrm{P}_{\mathrm{y}}\right)$, which gives the relative percentage of whites living in the tract of the average minority member and is interpreted as the likelihood of contact or interaction between minority group members and. It is defined by the equation:

$$
{ }_{\mathrm{x}} \mathrm{P}_{\mathrm{y}}^{*}=\left(\sum_{\mathrm{i}=1}^{\mathrm{n}} \mathrm{x}_{\mathrm{i}} / \mathrm{X}\left(\mathrm{y}_{\mathrm{i}} / \mathrm{t}_{\mathrm{i}}\right)\right) \times 100
$$

where $\mathrm{x}_{\mathrm{i}}, \mathrm{y}_{\mathrm{i}}, \mathrm{n}$, and $\mathrm{X}$ are defined as before and $\mathrm{t}_{\mathrm{i}}$, indicates to total population of tract $\mathrm{i}$ (Massey and Denton, 1988b). 
This index likewise varies from 0 to 100 and represents the percentage of whites living in the tract of the average minority group member. It has also been interpreted to represent the likelihood of residential interaction between minority group members and whites (Lieberson, 1981). For each MSA in the dataset, we computed dissimilarity indices to measure the degree to which blacks, Hispanics, and Asians in each income quintile are segregated from whites of any income; and in similar fashion, we computed $\mathrm{P}^{*}$ interaction indices by income quintile to measure the degree to which blacks, Hispanics, and Asians of different incomes are likely to interact with whites of any income.

Perhaps the most serious consequence of racial segregation is not that it reduces contact with whites per se, but that it increases the likelihood of contact with the poor while reducing the likelihood of contact with the affluent of any race (Massey, 1990; Massey and Fischer, 2000; Quillian, 2012). Thus we also adapted the $\mathrm{P}^{*}$ index to measure the degree to which blacks, Hispanics, and Asians in different income quintiles are likely to interact with poor and affluent persons regardless of race. This exercise used the same formula as Equation (2), except that $y_{i}$ was defined to refer to either poor or affluent persons, defined as those in the bottom and top quintiles of the household income distribution, respectively.

These computations yield four basic measures of segregation that we examine for blacks, Hispanics, and Asians by income quintile and census year: minority dissimilarity from whites, minority interaction with whites, minority interaction with the poor, and minority interaction with the affluent. These indices provide the basis for our descriptive analysis of trends in residential segregation and spatial interaction across census dates from 1970 to 2010. In our multivariate analysis, however, we turn our attention to identifying metropolitan characteristics associated with changes in minority-white segregation and minority-white interaction as minority income rises, and with changes in the exposure of minority members to poverty and affluence as their incomes increase. That is, we seek to identify which metropolitan factors promote the process of spatial assimilation as income rises.

In doing so, we focus on the year 2010 and calculate the difference between minority-white dissimilarity indices computed in the first and fifth income quintiles; and likewise to assess the prospects for greater interaction with whites with rising minority income we take the difference between minority-white interaction indices computed in the fifth and first income quintiles. Similarly, to measure the extent to which exposure to neighborhood poverty is reduced by rising minority income we take the difference between minority-poor interaction indices in the fifth and the first quintiles; and to measure the extent to which exposure to affluence is increased by rising minority incomes we take the difference between minorityaffluent interaction indices computed for in the first and fifth quintiles.

The foregoing computations yield four dependent variables for a cross-metropolitan regression analysis of how rising income affects four aspects of race-class segregation: the decrease in segregation from whites that minority group members can expect to achieve by moving from the bottom to the top of the income distribution; the increase in interaction with whites that minorities can expect from this income gain; the expected decrease in interaction with the poor associated with this income gain; and the expected increase in interaction with the affluent associated with a move from the top to the bottom of the income 
hierarchy. These outcomes yield a cross-sectional analysis of residential circumstances in metropolitan America as of 2010, asking which variables are associated with the size of differentials in the degree of minority desegregation and spatial assimilation between the first and fifth income quintiles in that year.

Our explanatory variables are defined in Table 1 and come from Rugh and Massey's (2014) prior analysis of overall trends in residential segregation and spatial isolation since 1970. Following the lead of Stephens-Davidowitz (2013), they developed an index of anti-black prejudice using Google Trends to tabulate relative frequencies for searches on the word "nigger" by metropolitan statistical area (MSA); and building on this idea they developed a similar index of anti-Latino sentiment by tabulating relative frequencies for searches on the term "Illegal Alien" by MSA (see the top panel of Table 1). They were unable, however, to use search frequencies on any derogatory terms for Asians to develop an index of anti-Asian prejudice.

The Rugh-Massey model also included the percentage of blacks, Hispanics, and Asians in each MSA, given that sociologists have long hypothesized that minority group threats increase with group size (Blalock, 1967; Blau, 1977; Lieberson, 1981). In addition to these group-specific indicators, the model assesses the effects of basic metropolitan characteristics. Population-related indicators include the log of population size, the percentage foreign born, the percentage aged 75 or over, and the percentage of homeowners in each MSA. Research has generally shown that minority segregation is greater in larger MSAs (Massey and Denton, 1987, 1988b), those that have more foreign born residents (Denton and Massey, 1988; Iceland and Scopilliti, 2008) and those that house more elderly (Farley and Frey, 1994).

Indicators of industrial organization include the percentage of workers in manufacturing; the percentage in finance, insurance, and real estate; and the percentage in education, along with the log of the military population, the percentage of workers in unions, and the number of patents per capita. In general, MSAs with large manufacturing sectors and high rates of unionization display higher levels of segregation (Lieberson, 1981; Massey and Denton, 1993) whereas those hosting "creative class" service industries, such as finance, insurance, and real estate, tend to be more diverse and less segregated (Florida, 2014). MSAs with colleges and universities and military installations also tend to be more racially integrated (Farley and Frey, 1994).

Given that MSAs are constructed from counties, we also control for the percentage of MSA residents who are considered urban (living in tracts with greater than 1000 persons per square mile). Other indicators of urbanism include the violent crime rate, the median year in which housing was built, and the permissiveness of density zoning in the MSA's suburbs. Whites continue to associate black neighborhoods with higher rates of crime and for this reason resist integration (Quillian and Pager, 2010; Emerson et al., 2001); MSAs with newer housing stocks built after the civil rights era tend to be less segregated than those areas built up in earlier periods (Farley and Frey, 1994); and MSAs surrounded by suburbs with more permissive density zoning regimes tend to be more integrated on the basis of both race and class (Rothwell and Massey, 2009, 2010). Building on work by Pendall et al. (2006), 
Rothwell and Massey (2009) constructed an instrumental variable to measure the permissiveness of density zoning across suburbs, one that Rugh and Massey (2014) adopted for their analysis and we also employ here.

Finally, we control for geographic location by including dummy variables indicating region (using the Midwest is the reference category), coastal residence, and location along the Mexico-U.S. border. Coastal areas tend to have more restrictive building codes, higher housing costs and thus greater segregation by race and class (Glaeser and Gyourko, 2008) whereas levels of Hispanic segregation have historically been higher along the Mexican border (Grebler et al., 1970; Massey, 1979a).

\section{Trends segregation by income}

Before turning to our descriptive analysis of trends and patterns of residential segregation by race and income, in Fig. 1 we review trends in the relative distribution of household income by quintile in the national income distribution for non-Hispanic whites, Asians, Hispanics, and blacks. If incomes were equally distributed within each group, all the income curves would be flat horizontal lines at the $20 \%$ level. Obviously, however, there are clear differences in the slope and direction of the income curves between whites and Asians, on the one hand, and Hispanics and blacks, on the other. The curves of the former two groups are upward sloping moving left to right, indicating a greater concentration of income at the top of the distribution; but those for the latter two groups are downward sloping, indicating a greater concentration of income at the bottom of the income hierarchy.

In 1970, for example, around 15\% of non-Hispanic whites (henceforth simply called whites) were in the lowest nationwide quintile of household income while $24 \%$ were in the highest. In contrast, among blacks $37 \%$ were located in the lowest income quintile compared with only $9 \%$ in the highest. Similarly, in $198019 \%$ of Asians fell into the lowest income quintile and $24 \%$ occupied the highest, whereas $29 \%$ of Hispanics fell into the lowest quintile and just $11 \%$ into the highest. Over time, moreover, both African Americans and Hispanics have shifted toward greater income equality (with the curve flattening out) while whites and Asians have moved toward greater inequality (with the slope of the curve increasing).

Between 1970 and 2010, for example, the percentage of blacks in the lowest income quintile dropped from $37 \%$ to $29 \%$ while the percentage in the top quintile increased from 9 to $13 \%$. Among Hispanics the corresponding shifts were from $29 \%$ to $22 \%$ in the lowest quintile and $11 \%-14 \%$ in the highest quintile. In contrast, the percentage of whites in the lowest quintile remained stable at around 15\% in both 1970 and 2010 while the percentage in the top quintile rose from $24 \%$ to $27 \%$. Among Asians, meanwhile, the percentage in the lowest quintile actually fell from $19 \%$ in 1980 to $14 \%$ in 2010 while the percentage in the highest quintile rose quite sharply from $24 \%$ to $36 \%$.

Fig. 2 illustrates how these shifts in the relative distribution of income were expressed spatially by plotting weighted average indices of dissimilarity from whites by income quintile for Asians, Hispanics, and African Americans, using the size of the class-specific minority population in each MSA as weights. The indices thus reflect the level of 
segregation experienced by the average minority resident in that income category across all metropolitan areas under study. In general, tract-based dissimilarity indices above 60 are considered "high" whereas those below 30 are viewed as "low," with those in-between taken as "moderate" (Massey and Denton, 1993). For ease of interpretation the y-axis in all graphs ranges from 30 to 90 with the value 60 highlighted in bold across income categories to separate the high from moderate levels of residential segregation.

A quick glance at the figure reveals that levels of income and residential segregation from whites have been inversely related for Hispanics and Asians throughout the forty-year period. In 1970, Hispanic-white segregation fell from an index value of 57 in the lowest quintile to around 40 in the highest. Likewise in 1980 Asian-white segregation dropped from 66 in the lowest quintile to 56 in the highest. Clearly, then, as early as 1970 rising income bought about significant racial desegregation for Hispanics and Asians, with declines of 30\% and $15 \%$, respectively in the degree of dissimilarity from whites moving from the top to the bottom of the income distribution.

In contrast, African Americans in 1970 experienced no desegregation as incomes rose. Indeed, segregation levels actually increased slightly with household income, going from 80 in the lowest quintile to 82 in the highest. In 1980, this pattern of constant high segregation persisted, with the dissimilarity index going only from 80 in the lowest quintile to 77 in the highest. Consistent with earlier work, in 1990, we begin to see a drop in black-white segregation as income rises. In that year the average dissimilarity index fell from 74 in the bottom quintile to 65 in the top. The socioeconomic differential in black-white segregation continued to widen in 2000 and 2010, though not by much. In the former year segregation went from an index value of 72 in the lowest quintile to 61 in the highest and in the latter year the respective figures were 70 and 60. In other words, although black-white segregation varied by income as of 2010 (in contrast to patterns in 1970 and 1980), changes since 1990 have been rather slow, and even at the top of the income distribution average levels of blackwhite segregation remain in the high range, roughly where the poorest Hispanics stood forty years earlier. Thus, African Americans continue to experience greater difficulty than others in translating their income gains into residential integration with whites.

Segregation differentials by income also widened over time for Asians. Whereas in 1980 Asian-white segregation dropped from 66 to 56 moving from top to the bottom of the income distribution, by 2010 the shift was from 66 to 50, widening the class differential from 10 to 16 points. In contrast, among Hispanics there was little progress between 1970 and 2010. Whereas in the former year Hispanic-white segregation fell from a value 57 in the top quintile to 40 in the bottom quintile, in 2010 the respective figures were 54 and 39 , actually reducing the income-related spread from 17 to 15 points. Despite the lack of progress, however, as of 2010 the poorest Hispanics were still less segregated, on average, than the most affluent African Americans.

\section{Trends in white interaction by income}

We now turn to an examination of the potential for intergroup contact based on $\mathrm{P}^{*}$ interaction indices, which as noted earlier give the likelihood of within-tract contact between 
members of any two groups. Fig. 3 shows $\mathrm{P}^{*}$ indices indicating the likelihood of tract-level interaction with whites by income for Asians, Hispanics, and African Americans from 1970 to 2010. In these plots we have highlighted the 50\% threshold to indicate the point at which the neighborhood experienced by the average minority group member turns majority white. Points above this line thus indicate a likelihood of spatial interaction with whites of 50\% or more.

Once again the unique ecological situation of African Americans stands out. Although the likelihood of spatial interaction with whites generally rises with income for all three groups, among blacks it is 50\% or lower at all levels of income whereas for Asians and Hispanics it is well above $50 \%$ across all quintiles. In 1970 the likelihood curve for black contact with whites was virtually flat and very low, rising from $33 \%$ in the bottom quintile to just $36 \%$ in the top quintile. At this point in time, when discrimination in the sale and rental of housing had only been outlawed for two years and discrimination in mortgage lending was still legal, rising income did not buy African Americans much of an increase in the likelihood of contact with whites. The situation changed little by 1980. Although the slope of the curve increased somewhat, this was mainly because the likelihood of white contact actually fell in the lowest quintile, with the interaction index dropping from $33 \%$ to $27 \%$ in the first quintile, but rising just one point from $36 \%$ to $37 \%$ in the fifth quintile.

As in earlier graphs, the big change for African Americans came during the 1980s when the likelihood of white contact rose in all quintiles and the upward slope of contact by income increased. Between 1980 and 1990, for example, the black-white interaction index in the lowest quintile rose from $27 \%$ to $34 \%$ whereas in the highest quintile it went from $37 \%$ to $46 \%$, thereby increasing the incline of the curve. As we have seen before, however, the pace of change slowed down considerably after 1990 and as of 2010 the likelihood of interaction with whites stood at just 39\% for black households in the lowest income quintile and just under $50 \%$ for those in the highest quintile.

In contrast, among Hispanic households the likelihood of white contact in 2010 was $65 \%$ in the lowest category and $72 \%$ in the highest. Unlike blacks, however, Hispanic's average likelihood of interaction with whites declined over time. Indeed, in 1970 the likelihood of contact with whites was extremely high at all income levels, with the interaction index being $85 \%$ in the lowest income quintile and $92 \%$ in the highest. The large decline in the likelihood of white contact between 1970 and 2010 reflects the rapid increase in the percentage of Hispanics living in U.S. metropolitan areas, which naturally drove up their levels of spatial isolation (Rugh and Massey, 2014). In the nation as a whole, the percentage of Hispanics rose from $4.7 \%$ in 1970 to $17.3 \%$ in 2010, and according to the Pew Research Center in 2010 the average Hispanic percentage stood at $22 \%$ in the 60 largest metropolitan areas (Motel and Pattern, 2012).

Although the overall likelihood of Hispanic-white contact within neighborhoods may have fallen, however, it is still higher than the likelihood of white contact for African Americans at all income levels. Among Asians, meanwhile, the likelihood of white contact also fell, but the decline was small, in keeping with the smaller increase in their share of the population, which reached $5 \%$ in 2010. In that year the Asian-white interaction index stood at 58\% in 
the bottom quintile of income and $66 \%$ in the top quintile-much higher than the corresponding black values of $39 \%$ and $50 \%$.

\section{Trends in exposure to poverty and affluence}

Although black-white segregation and black spatial interaction with whites now vary by income, blacks are still quite segregated compared with Hispanics and Asians. Given that high levels of segregation are well known to interact with high levels of poverty and low levels of affluence within the segregated group to concentrate poverty and deconcentrate affluence spatially (Quillian, 2012), these findings imply that African Americans are still much more likely to be exposed to neighborhood disadvantage and much less likely to experience neighborhood advantage than other racial and ethnic groups in the United States.

Fig. 4 shows weighted average interaction indices indicating the likelihood of contact with persons from bottom percentile households for Asians, Hispanics, and African Americans from 1970 to 2010 . Indices above $20 \%$ are conventionally considered to indicate a "high" concentration of poverty, those above $40 \%$ indicate "extreme" concentrations, and those below $20 \%$ are taken to reflect a "low" concentration of poverty. These thresholds are highlighted in the figure for ease of interpretation. Looking at Fig. 4, it is immediately clear that African Americans of all incomes have experienced high concentrations of neighborhood poverty for most of the past four decades. Indeed, in 1980 black households in the bottom quintile experienced an extreme concentration of poverty. At this point in time, the likelihood of within-neighborhood contact with other poor households reached $43 \%$ among poor blacks.

Moreover, it was only in 2000 that the poverty interaction index fell below $20 \%$ for top quintile households, thus giving them a "low" concentration of poverty. In 2010 households in the fourth income quintile also hit this threshold. Since 1980 the curves have moved steadily downward more or less in parallel, indicating wholesale movement toward lower concentrations of poverty. This trend reflects the decline in average levels of black-white segregation rather than a decline in black poverty per se. From 1970 to 1990 the black poverty rate remained fairly constant at around 32\%; and although it dropped to $23 \%$ during the boom of the 1990s by 2010 it had risen back up to $27 \%$ (U.S. Census Bureau, 2015). As of 2010, the likelihood of contact with poor persons ranged from $33 \%$ in the bottom quintile to $16 \%$ in the top.

Hispanics also experience relatively high concentrations of poverty, though not quite as high as African Americans. As with blacks, poverty concentration rose for Hispanics between 1970 and 1980. At the latter date, indices of poverty concentration lay within the "high zone" at all levels of Hispanic income. Thereafter overall exposure to neighborhood poverty moved downward, though at a slower pace than among African Americans. As of 2010 the likelihood of contact with bottom-quintile households ranged from $28 \%$ in the lowest quintile to $14 \%$ in the highest quintile.

Compared with black and Hispanic households, the degree of poverty concentration experienced by Asians has always been considerably lower. Whereas in 1980 no black or 
Hispanic household experienced a concentration of poverty below 20\%, among Asians in that year the value was $16 \%$ in the fourth quintile and $13 \%$ in the fifth. By 2010 only Asian households in the bottom quintile displayed an index above this threshold (24\%), compared with values of $18 \%, 15 \%, 13 \%$, and $10 \%$ in the second, third, fourth, and fifth quintiles, respectively.

Turning to the other end of the income distribution, Fig. 5 shows $\mathrm{P}^{*}$ interaction indices computed to measure likelihood of within-tract exposure to top quintile households, with thresholds at the values of 20 and 40 once again highlighted. As expected, exposure to affluent households within neighborhoods increases with income for all groups, but the overall level of exposure to affluence is much higher and rises more sharply for Asians than Hispanics or African Americans. In 1970 the share of affluent households in the neighborhood of the average poor Asian stood at $14 \%$ and then rose steadily by income to reach $32 \%$ in the top quintile. In contrast, in 1970 the percentage affluent in the neighborhood of the average black household rose from only $8 \%$ in the bottom quintile to just $18 \%$ in the top quintile, and among Hispanics the increase from bottom to top went from $10 \%$ to $27 \%$.

Over time, exposure to the affluent rose for all racial groups, with increases in the interaction index occurring disproportionately in the fourth and fifth quintiles. For Hispanic and black households, particularly, increases in the bottom quintile were quite small, with the interaction index going from 10\% to 13\% for Hispanics between 1970 and 2010 and from $8 \%$ to $11 \%$ for African Americans over the same period, compared to a shift from $14 \%$ to 22\% among Asians between 1980 and 2010. By 2010 the likelihood of contact with persons from affluent households had increased to $28 \%$ for blacks in the top quintile and to $30 \%$ for top-quintile Hispanics, whereas among Asians the likelihood reached 42\%. Indeed, as of 2010, Asians were above the $20 \%$ threshold at all income levels whereas Hispanic households did not reach this mark until the fourth quintile and black households not until the top quintile, illustrating the greater difficulty upper income Hispanics and African Americans have in gaining access to affluent neighborhoods and their amenities.

\section{Income, desegregation, and spatial assimilation}

We now turn to an assessment of the factors associated with income-driven desegregation and spatial assimilation. From the earlier work of Rugh and Massey (2014) we know that, as of 2010, higher levels of minority-white segregation were strongly predicted by anti-black and anti-Latino prejudice, elevated minority proportions, large metropolitan populations, and greater shares of foreign born residents. Lower levels of segregation, meanwhile, were associated with more permissive density zoning in suburbs, larger military populations, and a newer housing stock. Rugh and Massey also found that segregation levels decreased as minority incomes increased. Here we examine how these metropolitan characteristics affect the degree to which minority group members are able to convert income gains into lower levels of minority-white segregation and higher levels of minority-white interaction.

The regression equations in Table 2 focus on two metropolitan-level outcomes: the decline in minority-white dissimilarity observed between the bottom and top quintiles of the 
minority income distribution and the increase in minority-white interaction associated with the same shift in income. Following Rugh and Massey (2014), we pooled black, Hispanic, and Asian dissimilarity and isolation indices together in a concatenated file, using dummy variables to indicate whether the index in question pertained to blacks or Hispanics (leaving Asians as the reference category) and then interacting these dummy variables with indices of anti-black and anti-Latino prejudice and then included them in the regression model along with other metropolitan characteristics to predict the degree of desegregation and spatial assimilation associated with increases in minority income.

The left-hand columns show the model predicting the decline in minority-white residential dissimilarity associated with minority income going from the lowest to highest quintilethat is, the total amount of desegregation that occurs as income rises from bottom to top as of 2010. The first panel reveals that black and Hispanic gains in income are associated with significantly less desegregation than gains in Asian income-6.9 dissimilarity points less for Hispanics moving from the bottom to the top of the income distribution and 7.6 points less for blacks. As seen in the second panel, higher levels of anti-black and anti-Latino prejudice are associated with more income-driven desegregation, suggesting that in metropolitan areas characterized by high levels of prejudice income is especially critical in bringing about desegregation. Each point increase in the anti-black index increases the income-related decline in black-white dissimilarity by 0.18 points and each point increase in the anti-Latino index increases the income-related decline in Hispanic-white dissimilarity by 0.13 points.

The remaining panels capture the effect of other metropolitan characteristics on the ability of minority group members to achieve integration with whites as incomes rise. Across metropolitan areas, greater income-driven integration is associated with larger shares of Asians and blacks in the population and higher percentages of homeowners as well as a greater share residing on urbanized land, more patents per capita, and a larger military population.

Income-driven desegregation is reduced by larger shares of people above age 75 and larger percentages of workers in manufacturing and education. Holding these effects constant, however, greater desegregation is associated with rising income in the northeast and in coastal regions of the United States. Thus the ability of minority group members to translate income gains into integrated neighborhood circumstances is greatest in more urbanized areas in the northeast and on the coasts with younger populations and a post-industrial service economy (lower employment in manufacturing and a high rate of innovation as indicated by more patents per capita).

The right-hand columns examine the effect of metropolitan characteristics on the ability of minority group members to achieve greater interaction with whites as income rises. The top panel shows that, other things equal, blacks experience a 2.25 greater increase in interaction with whites as income moves from the bottom to the top of the income compared with Asians and Hispanics. Likewise, each point increase in the percentage black raises the degree of interaction with whites by 0.34 points. The likelihood of minority-white interaction is also greater in large metropolitan areas. The positive association between minority-white interaction and violent crime suggests that in metropolitan areas with higher 
crime rates minority group members have a greater motivation to seek residence in white neighborhoods. Other things equal, interaction with whites is less likely in the south and the west and in areas with a large share of foreign born and a large military population, but more likely in the northeast. In sum, minority-white interaction tends to be greater in large northeastern areas with smaller immigrant and military populations and higher crime rates.

Table 3 examines how metropolitan characteristics affect the degree to which moving from the bottom to the top of the minority income distribution brings about less contact with the poor and more contact with the affluent. As shown in the left-hand columns, larger declines in minority exposure to poverty are associated with higher levels of anti-Latino prejudice, larger population size, larger shares employed in education, and higher rates of violent crime, whereas higher percentages of the foreign born and homeowners and a larger military population inhibit the ability of minority group members to translate income gains into lower levels of contact with the poor. Controlling for the foregoing factors, income-driven declines in minority exposure to poverty are greater in the Northeast, Midwest, and West than in the South and are lower in coastal areas of the nation.

The right hand columns of Table 3 reveal that the degree to which minority contact with the affluent rises as income increases is greater for Asians for Hispanics and blacks. Moving from the bottom to the top of the income distribution brings about an increase in the likelihood of contact with the affluent that is two points less for Hispanics and three points less for blacks than for Asians. Greater income-related increases in contact with the affluent are associated with higher levels of anti-Latino sentiment, a high percentage of Asians, a larger population size, a greater share of workers in finance, insurance, and real estate, more patents per capita, higher shares of urban land, and higher violent crime rates. The degree to which minority group members are able to translate income gains in exposure to affluence is inhibited by larger percentages of foreign born, elderly, and workers in manufacturing and is systematically lower in the South compared to the Northeast, Midwest, and West and also less in coastal areas as well. The ability to achieve co-residence with affluent people as minority incomes rise thus appears to be greater in large, highly urbanized metropolitan areas in coastal areas outside the south with younger populations, well-developed creative economies.

\section{Conclusion}

The residential structure of metropolitan America has grown increasingly complex in recent decades owing to several structural changes. On average, levels of black-white segregation have steadily decreased since 1970, though the declines have been quite uneven and many African Americans continue to live under conditions of hypersegregation, especially in large metropolitan areas (Massey and Tannen, 2015). Average levels of Asian-white and Hispanicwhite segregation, meanwhile, have not declined and in some cases have actually increased (Rugh and Massey, 2014), especially in areas with large concentrations of undocumented migrants (Hall and Stringfield, 2014). With respect to class, inequalities of income and wealth have risen sharply though unevenly over the decades, and the degree of segregation by income has increased (Reardon and Bischoff, 2011a; Reardon et al., 2015). 
The combined effect of these changes has been to reduce racial neighborhood inequalities since the 1970s, but in different ways for different groups (Firebaugh and Farrell, 2016). On average, white neighborhoods have become less advantaged while black and Hispanic neighborhood circumstances have improved somewhat over time, narrowing black-white and Hispanic-white disparities in neighborhood income and poverty (see also Timberlake and Iceland, 2007). Socioeconomic circumstances in Asian neighborhoods, meanwhile, have improved and now exceed those of whites, thereby narrowing Asian-white neighborhood inequality (see also Timberlake, 2002). Although rising income segregation has played some role in accounting for these trends, neighborhood inequalities are to a large extent driven by variation in racial residential segregation in combination with intergroup economic differentials across metropolitan areas (Osypuk et al., 2009; Quillian, 2012; Firebaugh and Farrell, 2016).

Although the foregoing work on neighborhood inequality clearly suggests that racial residential segregation produces racial neighborhood inequality, the current analysis provides evidence on a key mechanism by which this connection occurs: high levels of segregation and the racial prejudice and discrimination that cause it prevent members of segregated groups from translating their socioeconomic achievements into spatial assimilation with whites and achieving greater access to socioeconomically advantaged neighborhoods. Especially in 1970 and 1980 African Americans were highly segregated through metropolitan America and unable to achieve desegregation and access to the advantages of residence in predominantly white neighborhoods.

As overall black-white segregation levels fell after 1980, however, blacks were increasingly able to translate their income gains into integration and spatial assimilation into advantaged neighborhood circumstances, as expressed by the fact that black-white segregation since 1990 has come to decline with rising income. As of 2010, however, African Americans continued to remain quite segregated from whites, with dissimilarity indices in the "high" range above 60 at all levels of income. This pattern stands in stark contrast to Hispanics whose dissimilarity index values ranged from 54 in the bottom quintile of income to 39 in the top quintile, as well as to Asians whose values went from 66 at the bottom of the income distribution to 50 at the top. Even today the highest income black households are still more segregated than the poorest Hispanic households.

As a result of their higher overall levels of segregation and lesser ability to achieve integration with rising income, black households experience much lower likelihoods of spatial interaction with whites than Hispanics or Asians. Although minority-white $\mathrm{P}^{*}$ interaction indices have fallen at all levels of income for Asians and Hispanics because of their growing shares of the population, they remain well above 50 at all levels from income, in 2010 rising from values around 60 in the lowest income quintile to roughly 70 in the highest. In contrast, the black-white interaction index in 2010 rose from around 40 in the lowest quintile to just under 50 in the highest, yielding roughly a 20-point gap between high income blacks, on the one hand, and high income Hispanics and Asians, on the other.

High black segregation and a limited ability to achieve residential contact with whites as income rises also means that, compared with other groups, African Americans are less able 
to separate themselves from the poor and less able to arrange co-residence with affluent as their socioeconomic status increases. Asians generally experience the lowest levels of exposure to poverty. As of 2010 Asians in the lowest income quintile lived in a neighborhood that was around $25 \%$ poor while those in the highest quintile occupied a neighborhood that was only $10 \%$ poor. In contrast, blacks in the lowest quintile in 2010 inhabited a neighborhood that was 33\% poor while those in the top quintile inhabited one that was $15 \%$ poor. For Hispanics the respective figures were $27 \%$ poor in the bottom quintile and $14 \%$ poor in the top quintile.

As income rises, the percentage of affluent families within neighborhoods occupied by all minority group members increases, but the overall level of exposure to affluence and the rate of ascent is much greater for Asians than Hispanics or African Americans. In 2010, for example Asians in the lowest income quintile inhabited a neighborhood that was around 22 percent affluent, compared to a figure of $13 \%$ affluent for Hispanics and $10 \%$ for blacks in the bottom quintile. In the top quintile, the average Asian had come to occupy a neighborhood that was around $41 \%$ affluent, compared with one that was $30 \%$ affluent for Hispanics and $28 \%$ affluent for blacks. Put simply, the same increase in income buys blacks and Hispanics far less in the way of residential integration and spatial advantage than it does for Asians.

As noted by Firebaugh and Farrell (2016), residential segregation plays an outsized role in determining neighborhood inequalities, and this fact is illustrated by considering the residential circumstances of African Americans in the 21 metropolitan areas that Massey and Tannen (2015) identified as hypersegregated for blacks in 2010. As shown in Fig. 6, within these areas, which together house around a third of the metropolitan black population, the disadvantaged spatial position of African Americans is particularly acute. In hypersegregated America, the level of areas that black-white dissimilarity remains close to 70 even for the most affluent blacks, among whom the white interaction index stands at only 40 , the probability of contact with the poor remains high at around 20, and the probability of contact with the affluent is just $27 \%$.

Multivariate analyses indicate that after controlling for a variety of metropolitan characteristics, blacks achieve far less integration with whites and contact with the affluent as income rises compared to Asians. Those metropolitan areas most conducive to minority racial integration and co-residence among the affluent as income rises are large, urbanized but non-hypersegregated areas located in the northeast with lower percentages of immigrants, less manufacturing, and higher rates of innovation-in short the classic postindustrial creative class economies identified by Florida (2014). Whatever the local economic terrain, however, income continues in 2010 to buy less access to affluence and integration for blacks than other groups.

Although the current analysis descriptively analyzed how the relationship between minority income and minority segregation changed over time from 1970 to 2010, a weakness is that owing to space and data limitations our multivatiate analysis was cross-sectional, focusing on the year 2010. Although we may have added value by updating findings on the relationship between segregation, spatial assimilation, and minority income, future work 
should focus on identifying how the determinants of residential segregation might have changed over time and how segregation's contribution to the contribution of poverty might have changed as a result. In particular, given that recent work by Sampson (2012), Sharkey (2013), and Chetty et al. (2016) underscores the critical importance of neighborhoods in the perpetuation of both advantage and disadvantage in U.S. society, greater attention should be paid to how the interplay of intergroup income inequality, intergroup segregation, income segregation within groups, and income segregation might have shifted over time to produce different spatial concentrations of affluence and poverty for African Americans, Asians, and Hispanics at different historical junctures.

\section{Acknowledgments}

The authors thank the National Institute for Child Health and Development for its support from grant 2 P2C HD047879.

\section{References}

Alba, Richard D. Italian Americans: into the Twilight of Ethnicity. Prentice-Hall; Englewood Cliffs, NJ: 1985.

Alba, Richard D.; Logan, John R. Analyzing locational attainments: constructing individual level regression models using aggregate data. Socio Methods Res. 1992; 20:367-397.

Alba, Richard D.; Nee, Victor. Remaking the American Mainstream: Assimilation and Contemporary Immigration. Harvard University Press; Cambridge: 2003.

Blalock, Hubert M. Toward a Theory of Minority-group Relations. Wiley; New York: 1967.

Blau, Peter M. Inequality and Heterogeneity: a Primitive Theory of Social Structure. Free Prfess; New York: 1977.

Charles, Camille Z. The dynamics of racial residential segregation. Annu Rev Sociol. 2003; 29:167207.

Chetty, Raj; Hendren, Nathaniel; Katz, Lawrence. The effects of exposure to better neighborhoods on children: new evidence from the moving to opportunity experiment. Am Econ Rev. 2016; 106:855902.

Denton, Nancy A.; Massey, Douglas S. Residential segregation of blacks, Hispanics, and Asians by socioeconomic status and generation. Soc Sci Q. 1988; 69:797-817.

Denton NA, Massey DS. Racial identity among caribbean Hispanics: the effect of double minority status on residential segregation. Am Sociol Rev. 1989; 54:790-808.

Duncan, Otis D.; Duncan, Beverly. The Negro Population of Chicago: a Study of Residential Succession. University of Chicago Press; Chicago: 1957.

Emerson, Michael O.; Yancey, George; Chai, Karen J. Does race matter in residential segregation? exploring the preferences of white Americans. Am Sociol Rev. 2001; 66(6):922-935.

Farley, Reynolds; Frey, William H. Changes in the segregation of whites from blacks during the 1980s: small steps toward a more integrated society. Am Sociol Rev. 1994; 59(1):23-45.

Firebaugh, Glenn; Farrell, Chad R. Still large, but narrowing: the sizable decline in racial neighborhood inequality in metropolitan America, 1980-2010. Demography. 2016; 53:139-164. [PubMed: 26685905]

Florida, Richard. The Rise of the Creative Class-revisited. Basic Books; New York: 2014.

Glaeser, Edward L.; Gyourko, Joseph. Rethinking Federal Housing Policy: How to Make Housing Plentiful and Affordable. AEI Press; Washington, DC: 2008.

Grebler, Leo; Moore, Joan W.; Guzman, Ralph C. The Mexican-american People: the Nation's Second Largest Minority. Free Press; New York: 1970.

Hall, Matthew; Stringfield, Jonathan. Undocumented migration and the residential segregation of mexicans in new destinations. Soc Sci Res. 2014; 47:61-78. [PubMed: 24913945] 
Iceland, John; Scopilliti, Melissa. Immigrant residential segregation in U.S. Metropolitan areas, 19902000. Demography. 2008; 45(1):79-94. [PubMed: 18390292]

Iceland, John; Sharpe, Cicely; Steinmetz, Erika. Class differences in african american residential patterns in U.S. Metropolitan areas: 1990-2000. Soc Sci Res. 2005; 34(1):252-266.

Iceland, John; Weinberg, Daniel H.; Steinmetz, Erika. Racial and Ethnic Residential Segregation in the United States, 1980-2000. U.S. Census Bureau; Washington, DC: 2002.

Iceland, John; Wilkes, Rima. Does Socioeconomic Status Matter? Race, Class, and Residential Segregation. Soc Probl. 2006; 52(2):248-273.

Lieberson, Stanley. Ethnic Patterns in American Cities. Free Press; New York: 1963.

Lieberson, S. A Piece of the Pie: Blacks and White Immigrants since 1880. University of California Press; Berkeley: 1981.

Logan, John R.; Molotch, Harvey L. Urban Fortunes: the Political Economy of Place. University of California Press; Berkeley: 1987.

Massey, Douglas S. Residential segregation of Spanish Americans in United States urbanized areas. Demography. 1979a; 16:653-664.

Massey DS. Effects of socioeconomic factors on the residential segregation of blacks and spanish Americans in United States urbanized areas. Am Sociol Rev. 1979b; 44:1015-1022.

Massey DS. Hispanic residential segregation: a comparison of mexicans, cubans, and puerto ricans. Sociol Soc Res. 1981; 65:311-322.

Massey DS. Ethnic residential segregation: a theoretical synthesis and empirical review. Sociol Soc Res. 1985; 69:315-350.

Massey DS. American apartheid: segregation and the making of the underclass. Am J Sociol. 1990; 96:329-358.

Massey, Douglas S.; Bitterman, Brooks. Explaining the paradox of puerto rican segregation. Soc Forces. 1985; 64:306-331.

Massey, Douglas S.; Brodmann, Stefanie. Spheres of Influence: the Social Ecology of Racial and Class Inequality. Russell Sage Foundation; New York: 2014.

Massey, Douglas S.; Denton, Nancy A. Spatial assimilation as a socioeconomic process. Am Sociol Rev. 1985; 50:94-105.

Massey DS, Denton NA. Trends in the residential segregation of blacks, Hispanics, and Asians. Am Sociol Rev. 1987; 52:802-825.

Massey DS, Denton NA. Suburbanization and segregation in U.S. Metropolitan areas. Am J Sociol. 1988a; 94:592-626.

Massey DS, Denton NA. The dimensions of residential segregation. Soc Forces. 1988b; 67:281-315.

Massey DS, Denton NA. Hypersegregation in U.S. Metropolitan areas: black and hispanic segregation along five dimensions. Demography. 1989; 26:373-393. [PubMed: 2792476]

Massey, DS.; Denton, NA. American Apartheid: Segregation and the Making of the Underclass. Harvard University Press; Cambridge, MA: 1993.

Massey, Douglas S.; Fischer, Mary J. Does rising income bring integration? new results for blacks, Hispanics, and Asians in 1990. Soc Sci Res. 1999; 28:316-326.

Massey, Douglas S.; Fischer, Mary J. How segregation concentrates poverty. Ethn Racial Stud. 2000; 23:670-691.

Massey, Douglas S.; Mullan, Brendan P. Processes of hispanic and black spatial assimilation. Am J Sociol. 1984; 89:836-873.

Massey, Douglas S.; Tannen, Jonathan. A research note on trends in black hypersegregation. Demography. 2015; 52:1025-1034. [PubMed: 25791615]

McDonald, John F.; McMillen, Daniel P. Urban Economics and Real Estate: Theory and Policy. Wiley; New York: 2010.

Motel, Seth; Pattern, Eileen. Characteristics of the 60 Largest Metropolitan Areas by Hispanic Population. Pew Research Center: Hispanic Trends; Washington, DC: 2012. http:// www.pewhispanic.org/2012/09/19/characteristics-of-the-60-largest-metropolitan-areas-byhispanic-population/ [Accessed on 10/16/15 at] 
Osypuk, Theresa L.; Galea, Sandro; McArdle, Nancy; Acevedo-Garcia, Dolores. Quantifying separate and unequal: racial-ethnic distributions of neighborhood poverty in metropolitan America. Urban Aff Rev. 2009; 45:25-65.

Park, Robert E.; Burges, Ernest W. Introduction to the Science of Sociology. University of Chicago Press; Chicago, IL: 1921.

Park, Robert E.; Burgess, Ernest W.; McKenzie, Roderick D. The City: Suggestions for Investigation of Human Behavior in the Urban Environment. University of Chicago Press; Chicago, IL: 1925.

Pendall, Rolf; Puentes, Robert; Martin, Jonathan. From Traditional to Reformed: a Review of Land Use Regulations in the Nation's 50 Largest Metropolitan Areas. DCL Brookings Institution; Washington: 2006.

Quillian, Lincoln. Segregation and poverty concentration: the role of three segregations. Am Sociol Rev. 2012; 77(3):354-379. [PubMed: 24648570]

Quillian, Lincoln; Pager, Devah. Estimating risk: stereotype amplification and the perceived risk of criminal victimization. Soc Psychol Q. 2010; 73(1):79-104. [PubMed: 20686631]

Reardon, Sean F.; Bischoff, Kendra. Income inequality and income segregation. Am J Sociol. 2011a; 116:1092-1153. [PubMed: 21648248]

Reardon, Sean F.; Bischoff, Kendra. Growth in the Residential Segregation of Families by Income 1970-2009. Russell Sage Foundation; New York: 2011b. Project US2010 Report

Reardon, Sean F.; Fox, Lindsay; Townsend, Joseph. Neighborhood income composition by household race and income. Ann Am Acad Political Soc Sci. 2015; 660:78-97.

Rothwell, Jonathan; Massey, Douglas S. The effect of density zoning on racial segregation in U.S. Urban areas. Urban Aff Rev. 2009; 44:799-806.

Rothwell JT, Massey DS. Density zoning and class segregation in U.S. Metropolitan areas. Soc Sci Q. 2010; 91(5):1123-1143. [PubMed: 21117332]

Rugh, Jacob S.; Massey, Douglas S. Segregation in post-civil rights America: stalled integration or end of the segregated century? DuBois Rev Soc Sci Res Race. 2014; 11(2):202-232.

Sampson, Robert J. Great American City: Chicago and the Enduring Neighborhood Effect. University of Chicago Press; Chicago, IL: 2012.

Sharkey, Patrick. Stuck in Place: Urban Neighborhoods and the End of Progress toward Racial Equality. University of Chicago Press; Chicago, IL: 2013.

Stephens-Davidowitz, Seth. [accessed 28.06.13] The Effects of Racial Animus on a Black Presidential Candidate: Using Google Search Data to Find what Surveys Miss. 2013. http:// www.people.fas.harvard.edu/ sstephen/papers/ RacialAnimusAndVotingSethStephensDavidowitz.pd

Taeuber, Karl E.; Taeuber, Alma F. Negores in Cities: Residential Segregation and Neighborhood Change. Aldine; Chicago, IL: 1965.

Timberlake, Jeffrey M. Separate, but how unequal? ethnic residential stratification, 1980 to 1990 . City Community. 2002; 1:251-266.

Timberlake, Jeffrey M.; Iceland, Jonathan. Change in racial and ethnic residential inequality in american cities, 1970-2000. City \& Community. 2007; 6:335-365.

U.S. Census Bureau. Historical Poverty Tables - People. U.S. Census Bureau; Washington, DC: 2015. at. https://www.census.gov/hhes/www/poverty/data/historical/people.html [accessed 10.16.15]

Waters, Mary C. Ethnic Options: Choosing Identities in America. University of California Press; Berkeley: 1990.

Wilkes, Rima; Iceland, John. Hypersegregation in the twenty-first century: an update and analysis. Demography. 2004; 41(1):23-36. [PubMed: 15074123] 


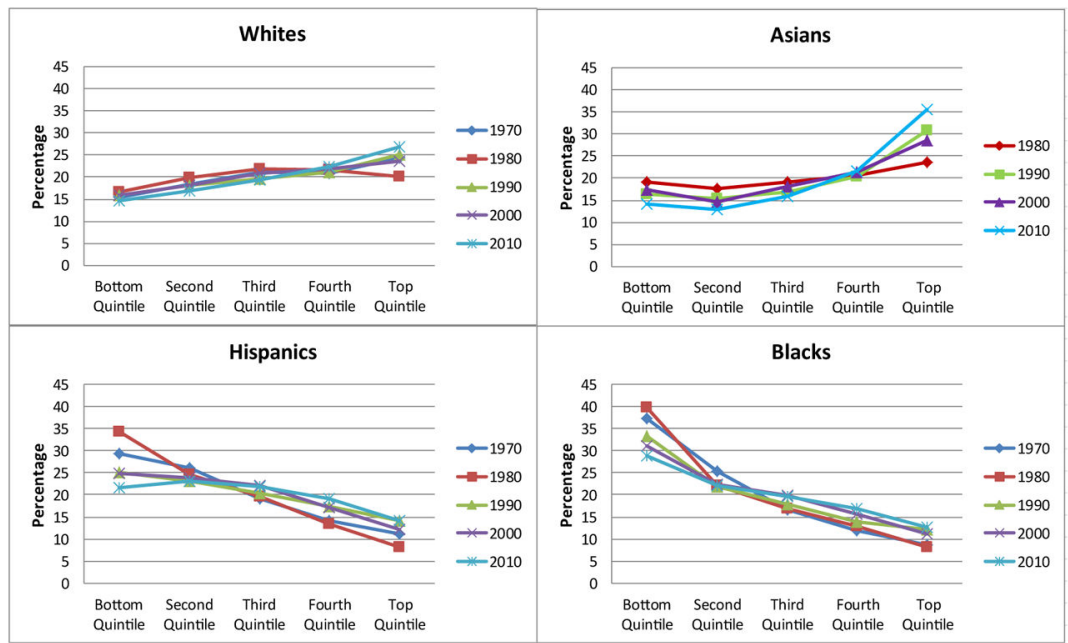

Fig. 1.

Personal income distribution by race 1970-2010. 

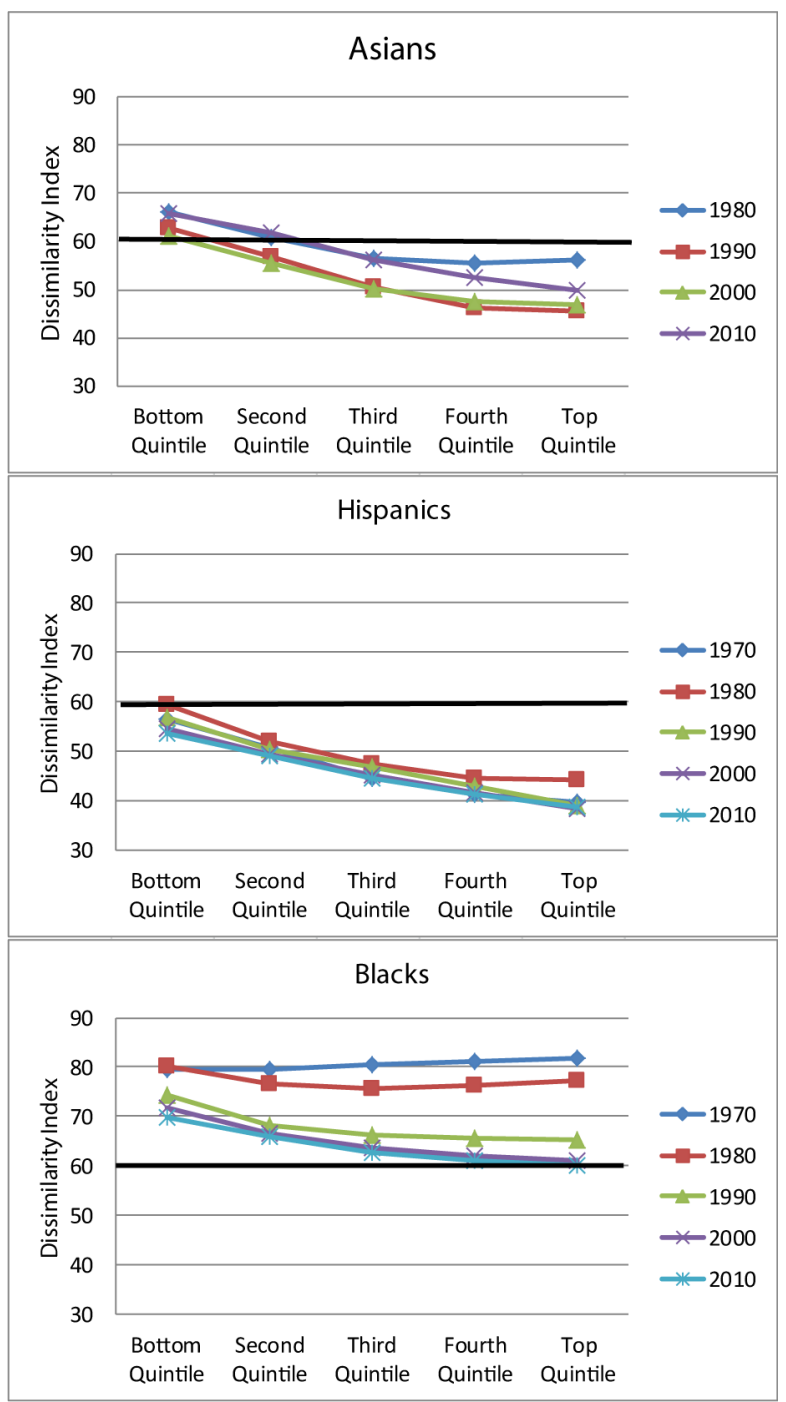

Fig. 2.

Segregation from whites by race and income 1970-2010. 


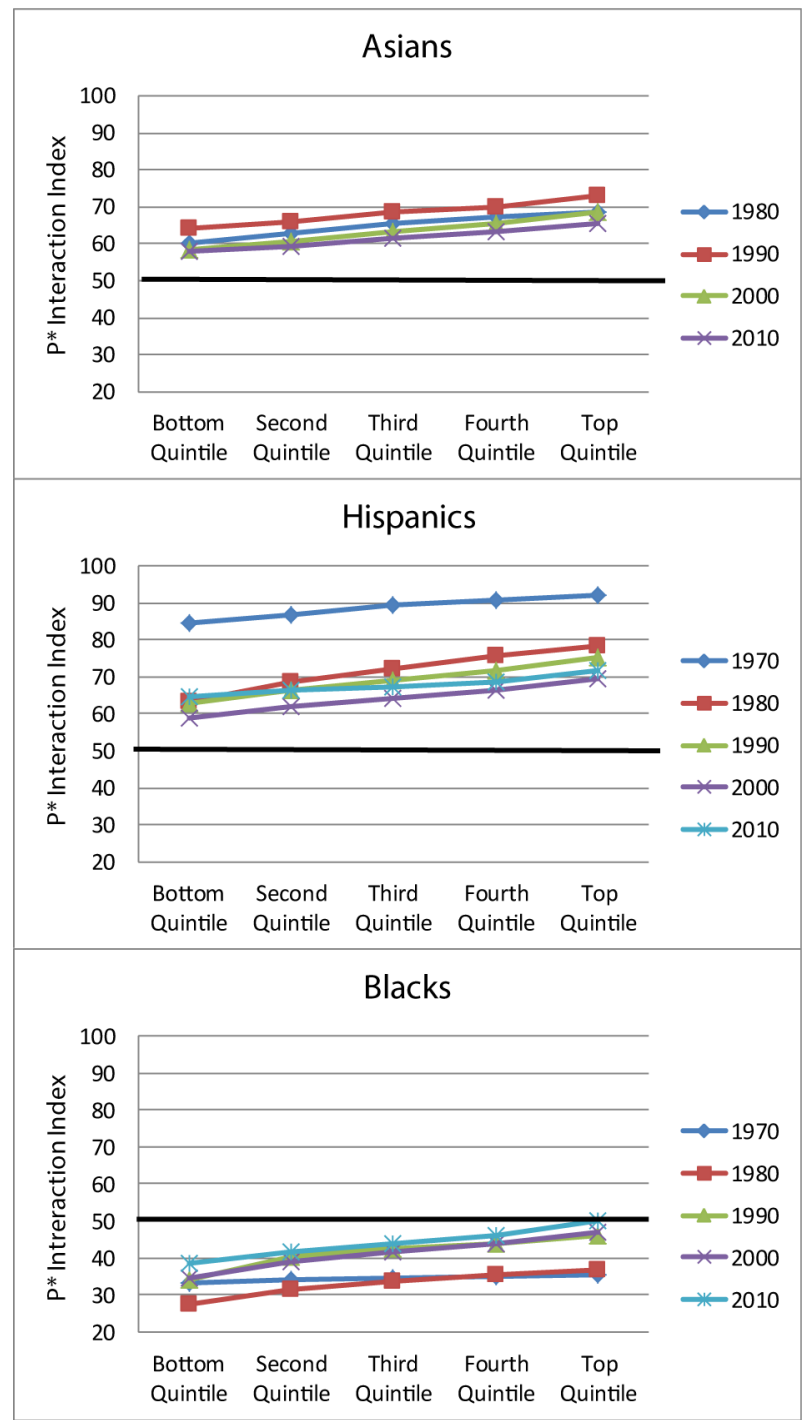

Fig. 3.

Probability of interaction with whites by race 1970-2010. 


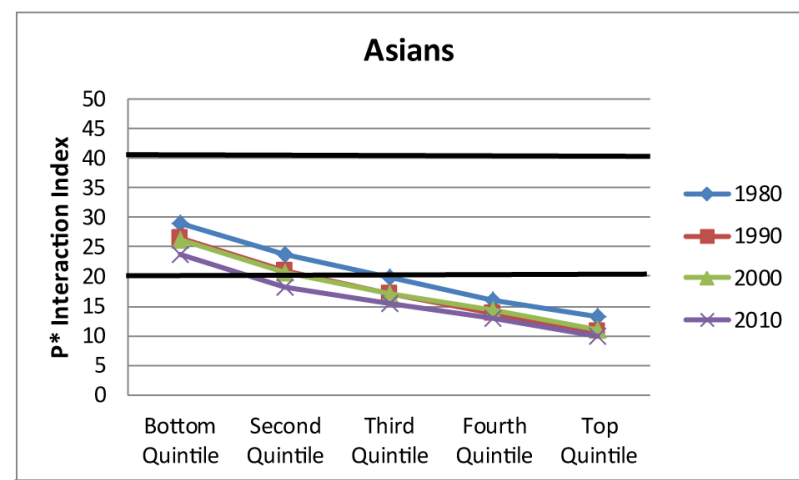

Hispanics
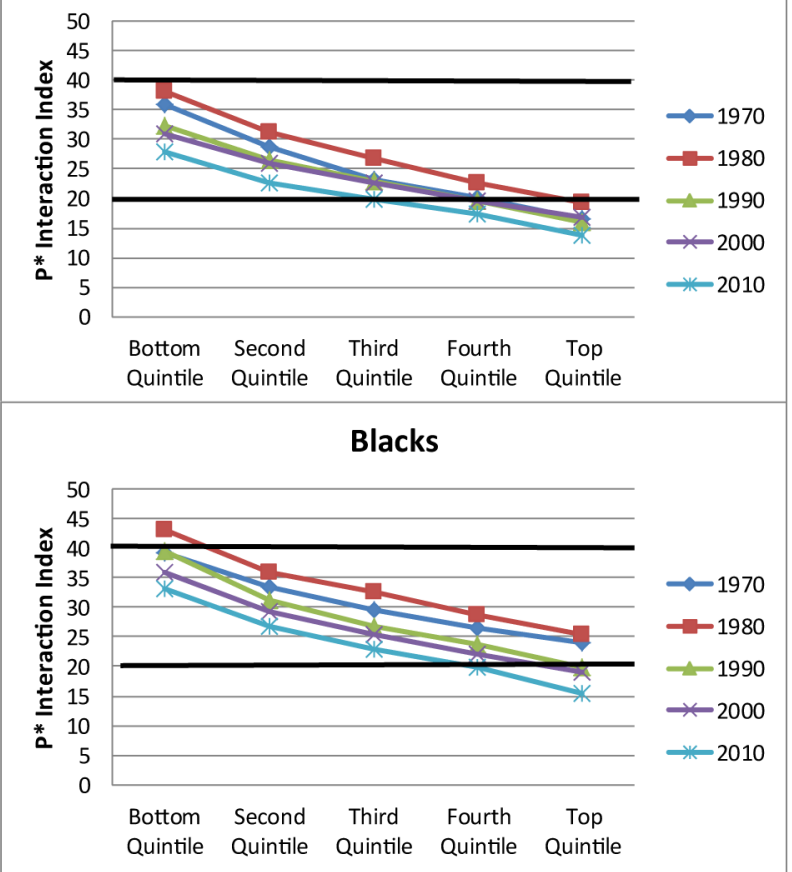

Fig. 4.

Exposure to neighborhood poverty by race 1970-2010. 

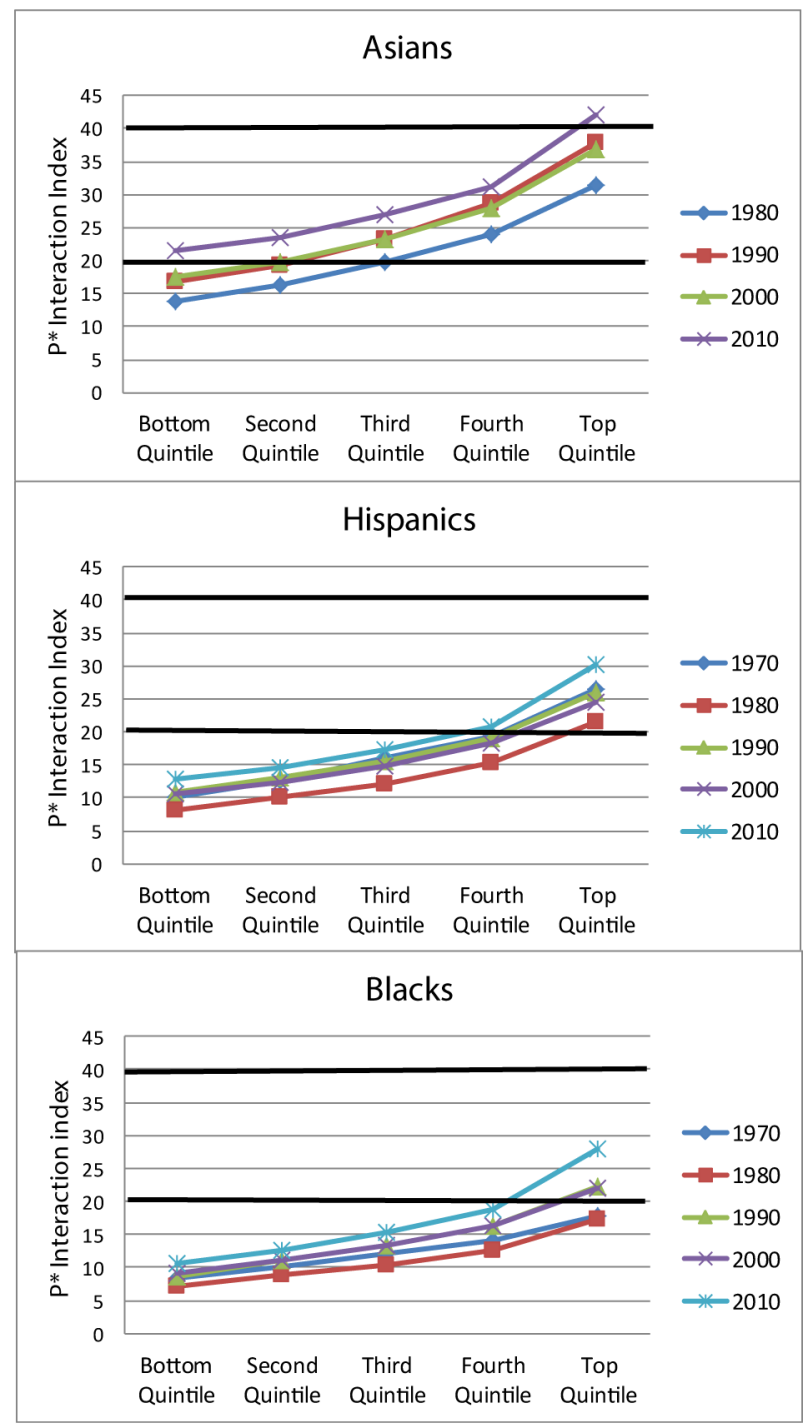

Fig. 5.

Exposure to neighborhood affluence by race 1970-2010. 


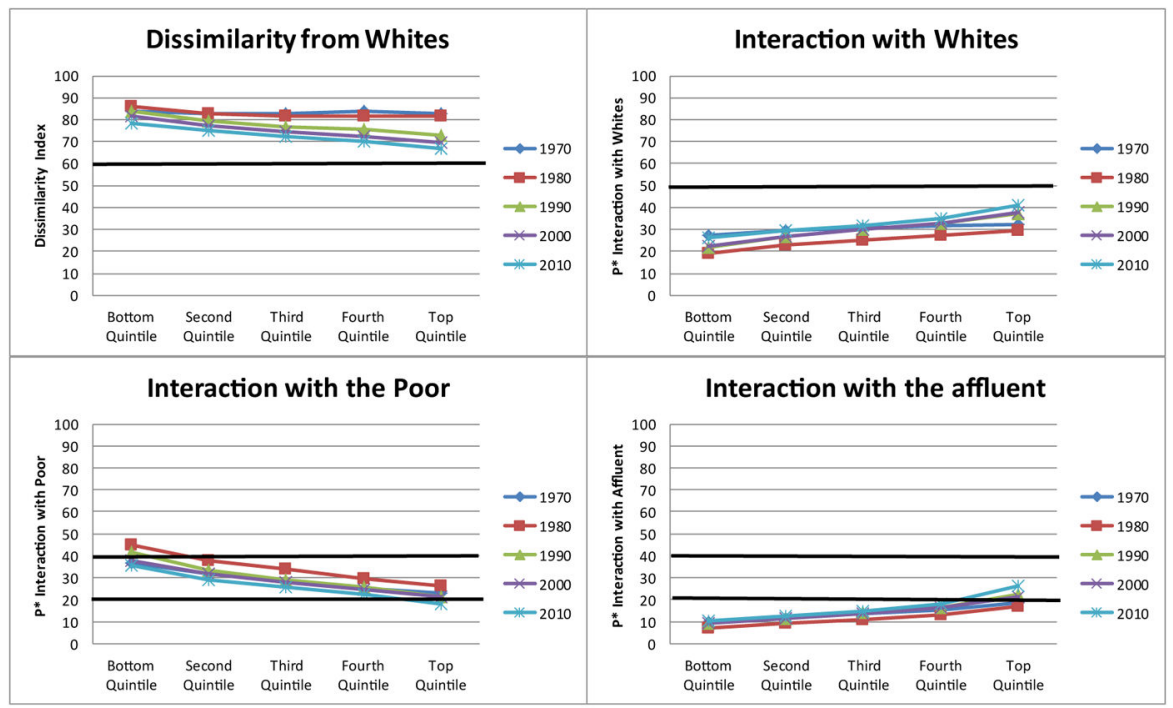

Fig. 6.

Indicators of segregation and interaction for African Americans in hypersegregated metropolitan areas. 


\section{Table 1}

Independent variables used to predict segregation and interaction outcomes for blacks, Hispanics, and Asians.

\begin{tabular}{|c|c|}
\hline Variable & Definition \\
\hline \multicolumn{2}{|l|}{ Racial prejudice } \\
\hline Anti-black index & Relative Frequency of Google Searches for word "Nigger" \\
\hline Anti-Latino index & Relative Frequency of Google Searches for "Illegal Alien" \\
\hline \multicolumn{2}{|l|}{ Minority composition } \\
\hline Percent black & Percentage black in MSA \\
\hline Percent Hispanic & Percentage Hispanic in MSA \\
\hline Percent Asian & Percentage Asian in MSA \\
\hline \multicolumn{2}{|l|}{ Population } \\
\hline Log MSA population & Log of Total MSA Population \\
\hline Percent foreign born & Percentage Foreign Born in MSA \\
\hline Percent Aged 75+ & Percentage of MSA Population Aged 75 or Greater \\
\hline Percent homeowner & Percentage of Homeowners in MSA \\
\hline \multicolumn{2}{|l|}{ Industrial organization } \\
\hline Percent manufacturing & Percentage of Workers in Manufacturing in MSA \\
\hline Percent FIRE & Percentage in Finance, Insurance \& Real Estate in MSA \\
\hline Percent education & Percentage of Workers in Education in MSA \\
\hline Log Military population & Log of Persons Housed in Military Quarters per 100,000 in MSA \\
\hline Percent unionized & Percentage of Workers in Union in MSA \\
\hline Patents per capita & Patents per 100,000 Persons in MSA \\
\hline \multicolumn{2}{|l|}{ Urbanism } \\
\hline Percent urban & Percent Urban in MSA \\
\hline Violent crime rate & Violent Crimes per 1,000 Persons in MSA \\
\hline Median year housing & Median Year MSA Housing was Built \\
\hline Zoning permissiveness & Instrumental Variable from Rothwell and Massey (2009) \\
\hline \multicolumn{2}{|l|}{ Geography } \\
\hline Northeast & Northeastern Census Region \\
\hline South & Southern Census Region \\
\hline West & Western Census Region \\
\hline Coastal & MSA Borders Atlantic, Pacific, or Gulf of Mexico \\
\hline Border & Located in State Bordering Mexico \\
\hline
\end{tabular}

Soc Sci Res. Author manuscript; available in PMC 2017 November 01. 


\section{Table 2}

Effect of selected variables on size of decline in minority-white residential dissimilarity and the increase in interaction probability with whites between bottom and top income quintiles in 2010 .

\begin{tabular}{|c|c|c|c|c|}
\hline \multirow[t]{2}{*}{ Independent variable } & \multicolumn{2}{|c|}{ Decline in dissimilarity Q1-Q5 } & \multicolumn{2}{|c|}{ Increase in interaction Q1-Q5 } \\
\hline & B & SE & B & SE \\
\hline \multicolumn{5}{|l|}{ Minority group } \\
\hline Asians & - & - & - & - \\
\hline Hispanics & $-6.879 * * *$ & 0.702 & 0.641 & 0.568 \\
\hline Blacks & $-7.576^{* * *}$ & 0.702 & $2.249 * * *$ & 0.568 \\
\hline \multicolumn{5}{|l|}{ Racial prejudice } \\
\hline Anti-black index (demeaned) & -0.054 & 0.038 & 0.021 & 0.031 \\
\hline Anti-black Index * black & $0.178 * * *$ & 0.046 & 0.071 & 0.037 \\
\hline Anti-Latino Index (demeaned) & 0.007 & 0.044 & 0.052 & 0.036 \\
\hline Anti-Latino index $*$ Hispanics & $0.131 *$ & 0.054 & $-0,058$ & 0.044 \\
\hline \multicolumn{5}{|l|}{ Minority composition } \\
\hline Percent Asian & $0.296^{*}$ & 0.126 & -0.009 & 0.102 \\
\hline Percent Hispanic & 0.057 & 0.062 & -0.019 & 0.050 \\
\hline Percent black & $0.252 * * *$ & 0.044 & $0.335^{* * *}$ & 0.036 \\
\hline \multicolumn{5}{|l|}{ Population } \\
\hline Log MSA population & 0.619 & 0.431 & $1.917 * * *$ & 0.349 \\
\hline Percent foreign born & 0.048 & 0.125 & $-0.230^{*}$ & 0.101 \\
\hline Percent Aged 75+ & $-1.392^{* * *}$ & 0.305 & 0.291 & 0.247 \\
\hline Percent homeowner & $0.357 * * *$ & 0.097 & 0.061 & 0.078 \\
\hline \multicolumn{5}{|l|}{ Industrial organization } \\
\hline Percent manufacturing & -0.179 & 0.095 & 0.041 & 0.077 \\
\hline Percent FIRE & 0.360 & 0.193 & -0.105 & 0.156 \\
\hline Percent education & $-0.431 * *$ & 0.132 & 0.080 & 0.107 \\
\hline Log Military population & $0.331 *$ & 0.143 & $-0.339^{* *}$ & 0.116 \\
\hline Percent unionized & 0.002 & 0.068 & -0.009 & 0.055 \\
\hline Patents per capita & $0.008 * * *$ & 0.002 & 0.000 & 0.002 \\
\hline \multicolumn{5}{|l|}{ Urbanism } \\
\hline Percent urban & $0.146^{* * *}$ & 0.044 & 0.012 & 0.035 \\
\hline Violent crime rate & 0.003 & 0.002 & $0.005^{* *}$ & 0.002 \\
\hline Median year housing & 0.025 & 0.060 & -0.001 & 0.059 \\
\hline Density permissiveness & -1.696 & 1.353 & 1.666 & 1.521 \\
\hline \multicolumn{5}{|l|}{ Geography } \\
\hline Northeast & $8.103^{* * *}$ & 1.279 & $4.685^{* * *}$ & 1.035 \\
\hline South & -1.610 & 1.198 & $-3.272^{* * *}$ & 0.970 \\
\hline West & -0.690 & 1.437 & -1.997 & 1.163 \\
\hline Coastal & $2.971^{* *}$ & 1.109 & 0.091 & 0.897 \\
\hline Border & 0.313 & 1.421 & 0.423 & 1.150 \\
\hline Constant & -73.554 & 116.5 & -28.540 & 94.610 \\
\hline
\end{tabular}




\begin{tabular}{llllll}
\hline Independent variable & \multicolumn{2}{l}{ Decline in dissimilarity Q1-Q5 } & & Increase in interaction Q1-Q5 \\
\cline { 2 - 3 } & B & SE & & B & SE \\
\hline $\mathrm{N}$ & 807 & 807 & 0.33 \\
Adj. R-squared & 0.46 & & \\
\hline
\end{tabular}




\section{Table 3}

Effect of selected variables on degree of decline in contact with the poor and increase in contact with affluent between bottom and top income quintiles in 2010 .

\begin{tabular}{|c|c|c|c|c|}
\hline \multirow[t]{2}{*}{ Independent variable } & \multicolumn{2}{|c|}{ Decline in contact with poor } & \multicolumn{2}{|c|}{ Increase in contact with affluent } \\
\hline & B & SE & $\mathbf{B}$ & SE \\
\hline \multicolumn{5}{|l|}{ Minority group } \\
\hline Asians & - & - & - & - \\
\hline Hispanics & -0.658 & 0.508 & $-2.009^{* * *}$ & 0.407 \\
\hline Blacks & 0.594 & 0.508 & $-3.025^{* * *}$ & 0.407 \\
\hline \multicolumn{5}{|l|}{ Racial prejudice } \\
\hline Anti-black index (demeaned) & 0.008 & 0.028 & 0.021 & 0.022 \\
\hline Anti-black index ${ }^{*}$ black & 0.032 & 0.033 & -0.034 & 0.027 \\
\hline Anti-Latino index (demeaned) & $0.081^{*}$ & 0.032 & $0.081^{* *}$ & 0.026 \\
\hline Anti-Latino index ${ }^{*}$ Hispanics & -0.011 & 0.039 & -0.040 & 0.031 \\
\hline \multicolumn{5}{|l|}{ Minority composition } \\
\hline Percent Asian & 0.091 & 0.091 & $0.185^{*}$ & 0.073 \\
\hline Percent Hispanic & 0.050 & 0.045 & 0.019 & 0.035 \\
\hline Percent black & 0.031 & 0.032 & 0.010 & 0.026 \\
\hline \multicolumn{5}{|l|}{ Population } \\
\hline Log MSA population & $1.745^{* * *}$ & 0.312 & $1.808^{* * *}$ & 0.250 \\
\hline Percent foreign born & $-0.478^{* * *}$ & 0.090 & $-0.208^{* *}$ & 0.072 \\
\hline Percent aged $75+$ & 0.349 & 0.221 & $-0.518^{* *}$ & 0.177 \\
\hline Percent homeowner & $-0.250^{* * *}$ & 0.070 & -0.064 & 0.056 \\
\hline \multicolumn{5}{|l|}{ Industrial organization } \\
\hline Percent manufacturing & -0.004 & 0.069 & $-0.152^{* *}$ & 0.055 \\
\hline Percent FIRE & 0.106 & 0.139 & $0.222^{*}$ & 0.112 \\
\hline Percent education & $0.367^{* * *}$ & 0.096 & 0.100 & 0.077 \\
\hline Log military population & $-0.282^{* *}$ & 0.103 & -0.050 & 0.083 \\
\hline Percent unionized & 0.038 & 0.050 & 0.02 & 0.04 \\
\hline Patents per capita & 0.001 & 0.001 & $0.004^{* * *}$ & 0.001 \\
\hline \multicolumn{5}{|l|}{ Urbanism } \\
\hline Percent urban & 0.019 & 0.032 & $0.100^{* * *}$ & 0.025 \\
\hline Violent crime rate & $0.003^{*}$ & 0.001 & $0.002^{*}$ & 0.001 \\
\hline Median year housing & 0.005 & 0.044 & 0.047 & 0.035 \\
\hline Density permissiveness & 0.913 & 0.979 & -0.576 & 0.785 \\
\hline \multicolumn{5}{|l|}{ Geography } \\
\hline Northeast & 1.340 & 0.925 & 1.030 & 0.741 \\
\hline South & $-1.692^{*}$ & 0.866 & $-1.506^{*}$ & 0.695 \\
\hline West & -1.701 & 1.039 & -1.468 & 0.833 \\
\hline
\end{tabular}




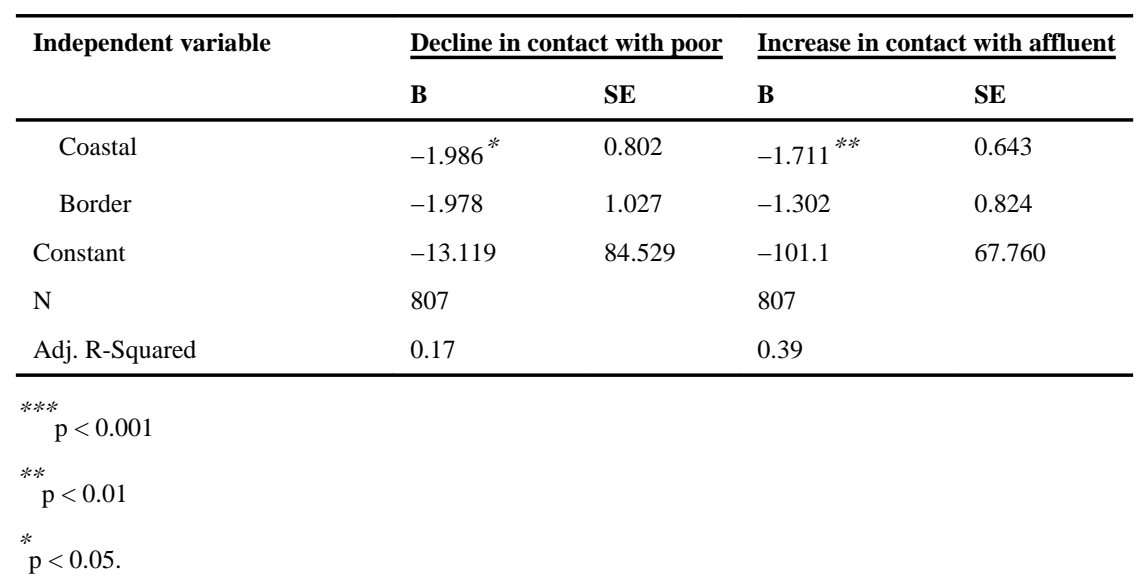

